The following is a pre-publication version of

Andrews, P. (2007) Mathematics teacher typologies or nationally located patterns of behaviour?, International Journal of Educational Research, 46(5) Pages 306-318

DOI: $\underline{10.1016 / j . i j e r .2007 .10 .001}$

Page numbers will not match those of the published version 


\title{
Mathematics teacher typologies or nationally located patterns of behaviour?
}

\author{
Paul Andrews \\ University of Cambridge, Faculty of Education
}

\begin{abstract}
This paper reports on a small-scale EU-funded study of the teaching of mathematics in the age range 10-14 in Flanders, England, Hungary and Spain. Drawing on video recordings of sequences of lessons taught on standard topics, and exploiting a coding schedule developed from live observations in each country, the inferable learning objectives of, and the didactic strategies teachers employ during, each of a lesson's episodes are examined. Two analyses were undertaken. The first, despite some common ground, indicated that teachers in each country behave in ways similar to teachers from the same country that distinguishes them from teachers elsewhere. The second identified typologies of teacher behaviour that were international in their teacher composition and challenged the robustness of the national script.
\end{abstract}

Keywords: quantitative research methods, cross-cultural comparisons, classroom teaching, video data, mathematics instruction

\section{Introduction}

Over the last fifteen years research has alluded to nationally-located patterns of mathematics teaching that distinguish teachers in one country from those of another (Schmidt, Jorde, Cogan, Barrier, Gonzalo, Moser et al., 1996). Various descriptions have been offered, including the cultural script (Stigler \& Hiebert, 1999), lesson signatures (Hiebert, Gallimore, Garnier, Givvin, Hollingsworth, Jacobs et al., 2003; Givvin, Hiebert, Jacobs, Hollingworth, \& Gallimore, 2005), and the characteristic pedagogical flow (Schmidt et al., 1996). The latter refers to "the pedagogical strategies and approaches typical of a set of lessons" that are "enacted repeatedly in a country's classrooms" (Cogan \& Schmidt, 1999, p. 71). Explanations for such patterns draw on beliefs that cultures "shape the classroom processes and teaching practices within countries, as well as how students, parents and teachers perceive them" (Knipping 2003, p. 282), to the extent that many of the processes of teaching are so "deep in the background of the schooling process ... so taken-for-granted... as to be beneath mention" (Hufton \& Elliott, 2000, p. 117).

This acknowledgement of the unarticulated has justified much comparative mathematics research because, "comparing teaching and learning processes in different countries promises to help us to become more aware of our own implicit assumptions concerning the learning of mathematics" (Knipping, 2003, p. 283). However, the veracity of the national script, on which much research is premised, seems not beyond question. LeTendre, Baker, Akiba, Goesling \& Wiseman's (2001) analysis of a TIMSS-related self-report survey of mathematics teachers beliefs and practices led them to conclude that teachers' core teaching practices and beliefs showed little cross-national variation. Such conclusions counter those of a more recent study, based on qualitative analyses of interview data, showing substantial differences between the espoused beliefs of teachers of mathematics in Hungary and England (Andrews, 2007a).

Caveats aside, it is no surprise that teaching practices in culturally dissimilar countries should differ and recent research has highlighted the influence of Socratic and Confucian philosophies on culturally West and culturally Chinese educational traditions (Leung, 2001; Tweed \& Lehman, 2002; Watkins, 2000) ${ }^{1}$. More surprising, perhaps, are educational

\footnotetext{
${ }^{1}$ The recently published $13^{\text {th }}$ ICMI study, Leung, F., Graf, K.-D. \& Lopez-Real, F. (Eds.) (2006) Mathematics education in different cultural traditions: A comparative study of East Asia and the West, New York, Springer,
} 
differences between countries of cultural similarity. For example, Sharpe (1997) notes how the Protestant and Catholic churches influenced the development of education in England and France while Osborn (2004) discusses how emphases on the individual, community and nation have informed educational practices and expectations in England, Denmark and France respectively. In respect of mathematics, Kaiser (2002) reports how differences in the philosophical underpinnings of the English and German educational systems influence how mathematics is taught. Such societal differences, it would seem to us, offer more support for the difference rather than the similarity conjecture, despite LeTendre et al.'s (2001) argument that "the act of teaching mathematics and the nature of this subject may be more influenced by the global institution of schooling than by national culture" (p. 12).

In this article we aim to examine the provenance of claims for both national and global scripts. In a first pass at the task, Givvin et al. (2005), working on data from the second TIMSS video study (TVS), found more strongly in favour of the national rather than the global script although the latter was strong on some of the characteristics under scrutiny like classroom interaction. However, and it is not our intention to repeat the criticism of the TVS coding schedule found in Clarke, Mesiti, Jablonka \& Shimizu (2006), the means by which TVS codes were developed and applied may have compromised the integrity of the study. For example, inter-coder reliability was achieved by means of percentage agreements; an approach which exaggerates agreement by ignoring the effects of chance. The codes were modifications of those developed for the first TIMSS video study of three countries and, despite an acknowledgement of the expanded group's seven, it was not clear to what extent such modifications addressed hitherto unseen aspects of mathematics classroom activity. Additionally, the use of time intervals may have masked the location and frequency of classroom events. In summary, while helpful in framing our study theirs may be less rigorously warranted than their article asserts.

\section{The METE project}

This article draws on the activities of the European Union-funded mathematics education traditions of Europe (METE) project; a comparative study of mathematics teaching in Flanders, England, Hungary and Spain. These countries ${ }^{2}$ reflect well not only the economic and geographical diversity of the continent but also variation of achievement on tests like TIMSS, PISA and their respective repeats. Importantly, the project countries were thought to have sufficient cultural similarity to pre-empt many of the well-documented problems of didactic transference.

The project focused on the age range 10 through 14 as, at this time, mathematics teaching shifts from an emphasis on mathematics as concrete and inductive to abstract and deductive. Also, to overcome some of the criticisms of earlier studies, the project focused on sequences of lessons taught on topics representative of all project countries' curricula. The topics, which had been agreed early in the project, were, for students in grades five or six, percentages and polygons, and for students in grades seven or eight, polygons again and linear equations. Percentages was chosen as an example of applicable arithmetic, polygons as a standard topic in geometry and a means of analysing how curricula develop a topic over several years, and linear equations because it represents an early topic in the study of formal algebra. Lastly, drawing on the learners' perspective study (LPS) (Clarke, 2006), attention was focused on teachers defined by local criteria as effective. In so doing we minimised the possibility of bias in respect of teacher selection by project teams while the observation of several successive lessons minimised the possibility of teachers presenting show-piece lessons.

offers a number of chapters that develop this particular theme.

${ }^{2}$ To simplify the discussion we construe Flanders, one of the two autonomous regions of Belgium, as a country. 


\begin{tabular}{|c|l|}
\hline $\begin{array}{c}\text { The following are the generic observable learning objectives of a teacher's actions. There } \\
\text { may be more than one observed within each episode of a lesson or, of course, there may be } \\
\text { none. The project team does not assert that this is a complete list. }\end{array}$ \\
\hline $\begin{array}{c}\text { Conceptual } \\
\text { knowledge }\end{array}$ & $\begin{array}{l}\text { The teacher is seen to encourage the conceptual development of his or her } \\
\text { students. }\end{array}$ \\
\hline $\begin{array}{c}\text { Derived } \\
\text { knowledge }\end{array}$ & $\begin{array}{l}\text { The teacher is seen to encourage the development of new mathematical } \\
\text { entities from existing knowledge }\end{array}$ \\
\hline $\begin{array}{c}\text { Structural } \\
\text { knowledge }\end{array}$ & $\begin{array}{l}\text { The teacher is seen to encourage links or connections between different } \\
\text { mathematical entities; concepts, properties and so on. }\end{array}$ \\
\hline $\begin{array}{c}\text { Procedural } \\
\text { knowledge }\end{array}$ & $\begin{array}{l}\text { The teacher is seen to encourage the acquisition of skills, procedures, } \\
\text { techniques or algorithms. }\end{array}$ \\
\hline $\begin{array}{c}\text { Mathematical } \\
\text { efficiency }\end{array}$ & $\begin{array}{l}\text { The teacher is seen to encourage learners' understanding or acquisition of } \\
\text { processes or techniques that develop flexibility, elegance or critical } \\
\text { comparison of working. }\end{array}$ \\
\hline $\begin{array}{c}\text { Problem- } \\
\text { solving }\end{array}$ & $\begin{array}{l}\text { The teacher is seen to encourage learners' engagement with the solution of } \\
\text { non-trivial or non-routine tasks. }\end{array}$ \\
\hline $\begin{array}{c}\text { Mathematical } \\
\text { reasoning }\end{array}$ & $\begin{array}{l}\text { The teacher is seen to encourage learners' development and articulation of } \\
\text { justification and argumentation. }\end{array}$ \\
\hline
\end{tabular}

Table 1: Working definitions of seven nferrable learning outcomes

Data collection was preceded by a year of live observations to develop, in a bottom-up manner, a framework for describing and analysing video-taped mathematics lessons. In brief, although full details can be found in Andrews (2007b), a week of live observations was undertaken in each project country. At least one lesson each morning was observed by at least one member from each project team and simultaneously video-recorded. During the afternoons, facilitated by home colleagues' linguistic and contextual support, discussions focused on constructing an accurate account of the lesson. Once this was agreed the videotape was replayed to facilitate the development of descriptive categories to be tested against subsequent and previous lessons. This iterative and constant comparative process led to the development of a three section framework of generic codes. The first section comprised seven observable learning objectives, the second four conceptions of mathematics underlying observed tasks, and the third ten observable didactic strategies. This article presents two differently focused analyses of the codes concerning learning objectives and didactic strategies for which working definitions can be seen in Tables 1 and 2 . 


\begin{tabular}{|c|c|}
\hline \multicolumn{2}{|c|}{$\begin{array}{l}\text { The following are the generic didactic strategies that teachers use to facilitate their learners' } \\
\text { ability to understand and use mathematics. With the exception of sharing, which is an } \\
\text { explicit public act, all strategies could be seen in both public (whole class) and private } \\
\text { (seatwork) contexts. }\end{array}$} \\
\hline $\begin{array}{l}\text { Activating prior } \\
\text { knowledge }\end{array}$ & $\begin{array}{l}\text { The teacher explicitly focuses learners' attention on mathematical } \\
\text { content covered earlier in their careers in the form of a period of } \\
\text { revision as preparation for activities to follow. }\end{array}$ \\
\hline $\begin{array}{l}\text { Exercising prior } \\
\text { knowledge }\end{array}$ & $\begin{array}{l}\text { The teacher explicitly focuses learners' attention on mathematical } \\
\text { content covered earlier in their careers in the form of a period of } \\
\text { revision unrelated to any activities that follow. }\end{array}$ \\
\hline Explaining & $\begin{array}{l}\text { The teacher explicitly explains an idea or solution. This may include } \\
\text { demonstration, explicit telling or the pedagogic modelling of higher } \\
\text { level thinking. In such instances the teacher is the informer with little } \\
\text { or no student input. }\end{array}$ \\
\hline Sharing & $\begin{array}{l}\text { The teacher explicitly engages learners in a process of public sharing } \\
\text { of ideas, solutions or answers. This may include whole-class } \\
\text { discussions in which the teacher's role is one of manager rather than } \\
\text { explicit informer. }\end{array}$ \\
\hline Exploring & $\begin{array}{l}\text { The teacher explicitly engages learners in an activity, which is not } \\
\text { teacher directed, from which a new mathematical idea is explicitly } \\
\text { intended to emerge. Typically this activity could be an investigation or } \\
\text { a sequence of structured problems, but in all cases learners are } \\
\text { expected to articulate their findings. }\end{array}$ \\
\hline Coaching & $\begin{array}{l}\text { The teacher explicitly offers hints, prompts or feedback to facilitate } \\
\text { their understanding of or abilities to undertake tasks or to correct errors } \\
\text { or misunderstandings. }\end{array}$ \\
\hline $\begin{array}{l}\text { Assessing or } \\
\text { evaluating }\end{array}$ & $\begin{array}{l}\text { The teacher explicitly assesses or evaluates learners' responses to } \\
\text { determine the overall attainment of the class. }\end{array}$ \\
\hline Motivating & $\begin{array}{l}\text { The teacher, through actions beyond those of mere personality, } \\
\text { explicitly addresses learners' attitudes, beliefs or emotional responses } \\
\text { towards mathematics. }\end{array}$ \\
\hline Questioning & $\begin{array}{l}\text { The teacher explicitly uses a sequence of questions, perhaps Socratic, } \\
\text { which lead pupils to build up new mathematical ideas or clarify or } \\
\text { refine existing ones. }\end{array}$ \\
\hline Differentiation & $\begin{array}{l}\text { The teacher explicitly attempts to treat students differently in terms of } \\
\text { the kind of tasks or activities, the kind of materials provided, and-or the } \\
\text { kind of expected outcome in order to make instruction optimally } \\
\text { adapted to the learners' characteristics and needs. }\end{array}$ \\
\hline
\end{tabular}

Table 2: Workling definitons of ten didactic strategies 
In each country a sequence of lessons, normally four or five, was videotaped on each of the four topics, with each topic being taught in a different school by a single teacher. Thus, with the exception of England where curricular guidelines regarding the time spent on different topics led to one topic receiving only three lessons, between fifteen (England) and twenty (Flanders) lessons were recorded in each country. Videographers were instructed to capture all teachers' utterances and as much of the work written on the board as possible. Teachers wore radio microphones while telescopic microphones were unobtrusively placed to capture student talk. Tapes were compressed and transferred to CD for later sharing. The episodes of each lesson, where an episode was defined as that part of the lesson during which the teacher's didactic intention remained constant, were then coded. The project team had agreed that all episodes had the potential for multiple coding and that any observed code should be applied. Additionally, the first two lessons in each sequence were transcribed using TransTool ${ }^{\circledR}$ and then, where appropriate, translated into English. This allowed colleagues to code other countries' lessons in order to assess inter-coder reliability. Cohen Kappa coefficients showed acceptable inter-coder reliability between the coders of England and Flanders $(\kappa=0.877)$, England and Hungary ( $\kappa=0.875)$ and England and Spain ( $\kappa=0.793)$.

According to Givvin et al. (2005, p. 313), a "key to making progress on uncovering national or global patterns...is to examine classroom teaching directly" and the use of video cameras offers several advantages over traditional methods such as direct observation (Stigler Gonzales, Kawanaka, Knoll, \& Serrano, 1999; Hiebert et al., 2003). However, it is important to acknowledge not only the impossibility of a video recording capturing all classroom discourse (Ulewicz \& Beatty, 2001) but also that what is recorded is inevitably a result, irrespective of any instructions, of decisions made by videographers (Clarke, 2006). In respect of our work, resources did not allow for more than a single camera in a classroom. Thus our data lacked the richness yielded by the LPS's three camera approach although, as our focus was explicitly on the actions of the teacher in the construction of mathematical understanding, our decision to focus on sequences of lessons taught on common topics yielded data of much greater richness than that of TVS with its single camera and single lesson per teacher. In summary, our view is that our data quality fell somewhere between those of the LPS and TVS but was entirely fit for our particular purpose.

\section{Results}

The reader is reminded that the data on which this article is based are, at best, ordinal and so non parametric tests have been used throughout. The reader is also reminded that although the sample was small and unlikely to be representative of all teachers in each country, each teacher was acknowledged, against nationally-located criteria, to be effective. Thus, tentative conclusions about "what teachers (or nations) believe about the aims of classroom instruction” (Givvin et al., 2005, p. 315) may be inferred. Also, as will become apparent, many of the statistical tests yielded such small probabilities as to make highly improbable the occurrence of type I errors - that hypotheses were rejected that should not have been.

The figures of Table 3, showing the frequencies of each country's episodes and the codes applied to them, highlight both similarities and differences. For example, although the mean Spanish and Hungarian lesson lengths differed by 12 minutes they comprised comparable numbers of episodes. The English lessons comprised more episodes per lesson with each, on average, being shorter than elsewhere and with fewer codes applied. The Hungarian lessons comprised the fewest episodes per lesson but with more codes applied to them. No Flemish attribute occupied an extreme position although most tended towards the lower rather than higher end of their respective spectra. The Spanish mean lesson was longer than all others by almost seven minutes which, with relatively few episodes recorded per lesson, yielded the 
longest episodes. Such findings indicate that the episodic structures of lessons differ across countries and offer some support in respect of national rather than global scripts.

\begin{tabular}{r|ccccc|} 
& Flanders & England & Hungary & Spain & All \\
\cline { 2 - 6 } Lessons & 20 & 15 & 18 & 16 & 69 \\
Episodes & 111 & 103 & 78 & 75 & 367 \\
Episodes per lesson & 5.6 & 6.9 & 4.3 & 4.7 & 5.3 \\
Mean lesson length & 50.1 & 53.1 & 45.9 & 58.2 & 51.5 \\
Mean episode length & 8.9 & 7.7 & 10.4 & 12.5 & 9.9 \\
Total codes applied & 512 & 437 & 547 & 446 & 1942 \\
Codes per episode & 4.6 & 4.2 & 7.0 & 5.9 & 5.3 \\
\cline { 2 - 6 }
\end{tabular}

Table 3: The number of lessons, the number of episodes they generated and the number of codes applied to them for each of the four project countries. All times are in minutes.

3.1 Analysis by country

$$
\text { F } \quad \text { E } \quad H \quad S
$$

Learning outcomes

$\begin{array}{lcccc}\text { Conceptual knowledge } & 68 & 79 & 68 & 77 \\ \text { Derived knowledge } & 5 & 1 & 6 & 3 \\ \text { Structural knowledge } & 14 & 1 & 44 & 15 \\ \text { Procedural knowledge } & 54 & 53 & 55 & 69 \\ \text { Efficiency } & 11 & 10 & 38 & 15 \\ \text { Problem-solving } & 7 & 20 & 31 & 39 \\ \text { Reasoning } & 32 & 30 & 49 & 25 \\ & & & & \\ & \text { Didactic strategies } & & & \\ \text { Activating prior knowledge } & 23 & 12 & 35 & 13 \\ \text { Exercising prior knowledge } & 3 & 8 & 5 & 0 \\ \text { Explaining } & 52 & 52 & 59 & 64 \\ \text { Sharing } & 61 & 60 & 97 & 61 \\ \text { Exploring } & 6 & 4 & 0 & 5 \\ \text { Coaching } & 39 & 54 & 45 & 76 \\ \text { Assessing } & 20 & 14 & 36 & 1 \\ \text { Motivating } & 10 & 13 & 46 & 56 \\ \text { Questioning } & 49 & 6 & 87 & 71 \\ \text { Differentiating } & 6 & 8 & 0 & 4 \\ \text { Total number of episodes } & 111 & 103 & 78 & 75\end{array}$

Table 4: Percentage of each country's episodes to which each code was applied.

The figures of Table 4 show the percentage of each country's episodes to which a particular code was applied. In respect of observable intentions, they indicate that all teachers emphasise conceptual and procedural knowledge which is supplemented by regular opportunities for mathematical reasoning. They also indicate that teachers rarely emphasise mathematics as derived knowledge. All remaining outcomes distinguish between the mathematical emphases of project countries with, for example, differences in the English and Hungarian emphases on 
structural knowledge being particularly obvious. In terms of the didactic strategies it can be seen that teachers explain regularly. They encourage their students to share their thinking and engage in regular bouts of coaching. It can also be seen that teachers, no matter where they work, rarely exercise prior knowledge, encourage their students to explore mathematical ideas or differentiate the work they set. The remaining strategies distinguish between the teaching of one country and another; the most obvious difference being in the use of questioning by English as compared with Hungarian teachers.

Mathematics as structural knowledge

\begin{tabular}{|c|c|c|c|c|c|c|c|c|c|c|}
\hline & $\mathrm{OA}$ & EA & $\mathrm{OP}$ & EP & Total & OP-EP & & $x^{2}$ & df & $\mathrm{p}$ \\
\hline Flanders & 95 & 92.2 & 16 & 18.8 & 111 & -2.8 & $\mathrm{~F} / \mathrm{E}$ & 16 & 1 & 0.0001 \\
\hline England & 102 & 85.6 & 1 & 17.4 & 103 & -16.4 & $\mathrm{~F} / \mathrm{H}$ & 20 & 1 & $<10^{-5}$ \\
\hline Hungary & 44 & 64.8 & 34 & 13.2 & 78 & 20.8 & $\mathrm{~F} / \mathrm{S}$ & 0 & 1 & 0.962 \\
\hline Spain & 64 & 62.3 & 11 & 12.7 & 75 & -1.7 & $\mathrm{E} / \mathrm{H}$ & 60 & 1 & $<10^{-}$ \\
\hline Total & 305 & & 62 & & 367 & & $\mathrm{E} / \mathrm{S}$ & 14 & 1 & 0.00 \\
\hline & & $x^{2}$ & $\mathrm{df}$ & p & & & $\mathrm{H} / \mathrm{S}$ & 16 & 1 & 0.00 \\
\hline
\end{tabular}

$61.23 \quad 10^{-12}$

Mathematical efficiency

\begin{tabular}{|c|c|c|c|c|c|c|c|c|c|c|}
\hline & OA & EA & OP & EP & Total & OP-EP & & $x^{2}$ & df & $\mathrm{p}$ \\
\hline Flanders & 99 & 91.9 & 12 & 19.1 & 111 & -7.1 & $\mathrm{~F} / \mathrm{E}$ & 0 & 1 & 0.791 \\
\hline England & 93 & 85.3 & 10 & 17.7 & 103 & -7.7 & $\mathrm{~F} / \mathrm{H}$ & 20 & 1 & $<10^{-5}$ \\
\hline Hungary & 48 & 64.6 & 30 & 13.4 & 78 & 16.6 & $\mathrm{~F} / \mathrm{S}$ & 1 & 1 & 0.436 \\
\hline \multirow[t]{3}{*}{ Spain } & 64 & 62.1 & 11 & 12.9 & 75 & -1.9 & $\mathrm{E} / \mathrm{H}$ & 22 & 1 & $<10^{-5}$ \\
\hline & 304 & & 63 & & 367 & & $\mathrm{E} / \mathrm{S}$ & 1 & 1 & 0.314 \\
\hline & & $x^{2}$ & $\mathrm{df}$ & $\mathrm{p}$ & & & $\mathrm{H} / \mathrm{S}$ & 11 & 1 & 0.0 \\
\hline
\end{tabular}

Problem-solving

\begin{tabular}{|c|c|c|c|c|c|c|c|c|c|c|}
\hline & OA & EA & $\mathrm{OP}$ & EP & Total & OP-EP & & $x^{2}$ & df & $\mathrm{p}$ \\
\hline Flanders & 103 & 86.2 & 8 & 24.8 & 111 & -16.8 & $\mathrm{~F} / \mathrm{E}$ & 8 & 1 & 0.004 \\
\hline England & 82 & 80.0 & 21 & 23.0 & 103 & -2.0 & $\mathrm{~F} / \mathrm{H}$ & 18 & 1 & 0.0001 \\
\hline Hungary & 54 & 60.6 & 24 & 17.4 & 78 & 6.6 & $\mathrm{~F} / \mathrm{S}$ & 28 & 1 & $<10^{-6}$ \\
\hline \multirow[t]{3}{*}{ Spain } & 46 & 58.2 & 29 & 16.8 & 75 & 12.2 & $\mathrm{E} / \mathrm{H}$ & 3 & 1 & 0.111 \\
\hline & 285 & & 82 & & 367 & & $\mathrm{E} / \mathrm{S}$ & 7 & 1 & 0.008 \\
\hline & & $\begin{array}{c}x^{2} \\
31.9\end{array}$ & $\begin{array}{c}\mathrm{df} \\
3\end{array}$ & $\begin{array}{c}\mathrm{p} \\
<10^{-6}\end{array}$ & & & $\mathrm{H} / \mathrm{S}$ & 1 & 1 & 0.305 \\
\hline
\end{tabular}

Table 5: Results of cross tabulations for the observed absence (OA), expected absence (EA), observed presence (OP) and expected presence (EP) for those learning outcomes identified by chi-square tests (seen below the cross tabulations) as representing significantly different proportional variation. Additionally, the results of pair-wise chi-square tests can be seen alongside. Bonferroni's correction indicates that only probabilities smaller than 0.0017 should be viewed as significant.

To understand more fully how the codes interacted with nationality cross tabulations, including chi-square tests, were undertaken. Those that yielded significant differences were subjected to nation by nation comparisons. In such circumstances, unless some form of 
correction is applied, the likelihood of type I errors may increase. Consequently, the Bonferroni correction, in which the maximum acceptable probability for rejecting the null hypothesis is divided by the number of pair-wise tests, was applied. With four countries, the maximum acceptable probability for the pair-wise tests was $p=0.05 / 6=0.0017$. However, such a conservative correction may increase the risk of type II errors - hypotheses that should have been rejected were not. This process led to the identification of three learning objectives and six didactic strategies and each is discussed below. 
Activating prior knowledge

\begin{tabular}{l|cccccccccc}
\multicolumn{1}{c}{} & OA & EA & OP & EP & Total & OP-EP & & $\chi^{2}$ & df & p \\
\cline { 2 - 8 } Flanders & 85 & 88.3 & 26 & 22.7 & 111 & 3.3 & F/E & 5 & 1 & 0.023 \\
England & 91 & 82.0 & 12 & 21.0 & 103 & -9.0 & F/H & 3 & 1 & 0.093 \\
Hungary & 51 & 62.1 & 27 & 15.9 & 78 & 11.1 & F/S & 3 & 1 & 0.082 \\
Spain & 65 & 59.7 & 10 & 15.3 & 75 & -5.3 & E/H & 14 & 1 & 0.001 \\
& 292 & & 75 & & 367 & & E/S & 0 & 1 & 0.737 \\
& & $\chi^{2}$ & df & p & & & H/S & 10 & 1 & 0.002 \\
& & 17.2 & 3 & 0.001 & & & & & &
\end{tabular}

Sharing

\begin{tabular}{|c|c|c|c|c|c|c|c|c|c|c|}
\hline \multirow[b]{2}{*}{ Flanders } & $\mathrm{OA}$ & \multirow{2}{*}{$\frac{\text { EA }}{34.8}$} & \multirow{2}{*}{$\begin{array}{c}\text { OP } \\
68\end{array}$} & \multirow{2}{*}{$\frac{\mathrm{EP}}{76.2}$} & \multirow{2}{*}{$\begin{array}{c}\text { Total } \\
111\end{array}$} & OP-EP & \multirow[b]{2}{*}{$\mathrm{F} / \mathrm{E}$} & \multirow{2}{*}{$\begin{array}{c}x^{2} \\
0\end{array}$} & \multirow{2}{*}{$\begin{array}{c}\mathrm{df} \\
1\end{array}$} & \multirow{2}{*}{$\begin{array}{c}\mathrm{p} \\
0.873\end{array}$} \\
\hline & 43 & & & & & -8.2 & & & & \\
\hline England & 41 & 32.3 & 62 & 70.7 & 103 & -8.7 & $\mathrm{~F} / \mathrm{H}$ & 41 & 1 & $<10^{-9}$ \\
\hline Hungary & 2 & 24.4 & 76 & 53.6 & 78 & 22.4 & $\mathrm{~F} / \mathrm{S}$ & 0 & 1 & 0.992 \\
\hline \multirow{3}{*}{ Spain } & 29 & 23.5 & 46 & 51.5 & 75 & -5.5 & $\mathrm{E} / \mathrm{H}$ & 41 & 1 & $<10^{-9}$ \\
\hline & 115 & & 252 & & 367 & & $\mathrm{E} / \mathrm{S}$ & 0 & 1 & 0.878 \\
\hline & & $x^{2}$ & $\mathrm{df}$ & p & & & $\mathrm{H} / \mathrm{S}$ & 36 & 1 & $<10^{-8}$ \\
\hline
\end{tabular}

Coaching

\begin{tabular}{|c|c|c|c|c|c|c|c|c|c|c|}
\hline & $\mathrm{OA}$ & EA & $\mathrm{OP}$ & EP & Total & OP-EP & & $x^{2}$ & $\mathrm{df}$ & $\mathrm{p}$ \\
\hline Flanders & 68 & 53.2 & 43 & 57.8 & 111 & -14.8 & $\mathrm{~F} / \mathrm{E}$ & 5 & 1 & 0.022 \\
\hline England & 47 & 49.4 & 56 & 53.6 & 103 & 2.4 & $\mathrm{~F} / \mathrm{H}$ & 1 & 1 & 0.400 \\
\hline Hungary & 43 & 37.4 & 35 & 40.6 & 78 & -5.6 & $\mathrm{~F} / \mathrm{S}$ & 26 & 1 & $<10^{-6}$ \\
\hline \multirow[t]{3}{*}{ Spain } & 18 & 36.0 & 57 & 39.0 & 75 & 18.0 & $\mathrm{E} / \mathrm{H}$ & 2 & 1 & 0.205 \\
\hline & 176 & & 191 & & 367 & & $\mathrm{E} / \mathrm{S}$ & 9 & 1 & 0.003 \\
\hline & & $\begin{array}{c}x^{2} \\
280\end{array}$ & $\begin{array}{c}\mathrm{df} \\
3\end{array}$ & $\underset{10^{-5}}{\mathrm{p}}$ & & & $\mathrm{H} / \mathrm{S}$ & 16 & 1 & 0.0001 \\
\hline
\end{tabular}


Table 6: Results of cross tabulations for the observed absence (OA), expected absence (EA), observed presence (OP) and expected presence (EP) for three didactic strategies identified by chi-square tests (seen below the cross tabulations) as representing significantly different proportional variation. Additionally, the results of pair-wise chi-square tests can be seen below the table. Bonferroni's correction indicates that only probabilities smaller than 0.0017 should be viewed as significant.

The figures of Table 5 show 16.4 fewer English episodes and 20.8 more Hungarian episodes coded for mathematics as structural knowledge than expected, with the pair-wise examination showing significantly fewer English episodes so coded than in any other project country and significantly more in Hungary than any other country. There were significantly more episodes coded for mathematical efficiency in Hungary than any other country with 16.6 more episodes than expected. There were significantly fewer episodes coded for problem-solving in Flanders than either Hungary or Spain with 16.8 fewer than expected episodes in Flanders and 12.2 more than expected in Spain.

The figures of Table 6 show significantly more episodes coded for the activation of prior knowledge in Hungary than either Spain or England, with 11.1 more episodes than expected in Hungary and 9.0 fewer such episodes than expected in England. There were significantly more episodes coded for sharing in Hungary than any other country with 22.4 more episodes than expected. There were significantly more episodes coded for coaching in Spain than either Hungary or Flanders with 18.0 more episodes than expected in Spain and 14.8 fewer in Flanders.

The figures of Table 7 show 14.2 more and 12.3 fewer episodes comprising the assessment of children's learning than expected in Hungary and Spain respectively. The latter reflected a significantly lower number of such episodes than in any other country while the former, represented a significantly higher number of such episodes than in either England or Spain. The use of strategies to motivate students appeared to polarise project episodes. There were 19.9 and 15.6 fewer episodes than expected in Flanders and England respectively and 14.3 and 21.2 more episodes than expected in Hungary and Spain respectively. The pair-wise tests showed that there were significantly fewer motivating episodes in Flanders than Hungary and Spain, similarly for England; while there were no differences between Flanders and England or Hungary and Spain. Questioning, too, created substantial divisions between the episodes of the different countries. There were 44.8 fewer episodes than expected in England and 39.5 and 16.0 more than expected in Hungary and Spain respectively. The former was significantly lower than in any other project country while the high frequency of Hungarian episodes was significantly greater than the Flemish.

In summary, as Givvin et al. (2005) note, the "degree to which activities with different purposes are evident in a set of lessons is an indicator of what teachers (or nations) believe about the aims of classroom instruction” (p. 315). The above shows not only much common ground in respect of the purposes of mathematics education but also substantial differences that, even acknowledging the small sample size, are unlikely to be due to chance. The rarity of mathematical efficiency and problem-solving in Flanders, the rarity of structural knowledge and mathematical efficiency in England, the privileging of structural knowledge, efficiency and problem-solving in Hungary and the high frequency of problem-solving in Spain all allude to different expectations in respect of the goals of mathematics teaching. Similarly, the comparative rarity of coaching, motivating and sharing in Flemish classrooms, the rarity of sharing, activation of prior knowledge, motivating and almost complete absence of questioning in England, the privileging of activating of prior knowledge, sharing, assessing, motivating and questioning in Hungary, together with high levels of coaching, motivating, questioning and low levels of assessing in Spain, offer distinctive commentaries on teachers' classroom behaviours that seem to locate individuals within well-defined didactic traditions. 
Assessing or evaluating

\begin{tabular}{|c|c|c|c|c|c|c|c|c|c|c|}
\hline \multirow[b]{2}{*}{ Flanders } & OA & EA & $\mathrm{OP}$ & EP & \multirow{2}{*}{$\begin{array}{c}\text { Total } \\
111\end{array}$} & OP-EP & \multicolumn{2}{|r|}{$x^{2}$} & $\mathrm{df}$ & $\mathrm{p}$ \\
\hline & 89 & 91.3 & 22 & 19.7 & & 2.3 & $\mathrm{~F} / \mathrm{E}$ & 1 & 1 & 0.222 \\
\hline England & 89 & 84.8 & 14 & 18.2 & 103 & -4.2 & $\mathrm{~F} / \mathrm{H}$ & 6 & 1 & 0.014 \\
\hline Hungary & 50 & 64.2 & 28 & 13.8 & 78 & 14.2 & $\mathrm{~F} / \mathrm{S}$ & 18 & 1 & 0.0001 \\
\hline \multirow[t]{3}{*}{ Spain } & 74 & 61.7 & 1 & 13.3 & 75 & -12.3 & $\mathrm{E} / \mathrm{H}$ & 12 & 1 & 0.001 \\
\hline & 302 & & 65 & & 367 & & $\mathrm{E} / \mathrm{S}$ & 10 & 1 & 0.001 \\
\hline & & $\begin{array}{c}x^{2} \\
37.9\end{array}$ & $\begin{array}{c}\mathrm{df} \\
3\end{array}$ & $\begin{array}{c}\mathrm{p} \\
10^{-7}\end{array}$ & & & $\mathrm{H} / \mathrm{S}$ & 36 & 1 & $<10^{-8}$ \\
\hline
\end{tabular}

\begin{tabular}{|c|c|c|c|c|c|c|c|c|c|c|}
\hline \multicolumn{11}{|c|}{ Motivating } \\
\hline \multirow[b]{2}{*}{ Flanders } & $\mathrm{OA}$ & EA & $\mathrm{OP}$ & EP & \multirow{2}{*}{$\begin{array}{c}\text { Total } \\
111\end{array}$} & \multirow{2}{*}{$\begin{array}{c}\text { OP-EP } \\
-19.9\end{array}$} & \multirow[b]{2}{*}{$\mathrm{F} / \mathrm{E}$} & \multirow{2}{*}{$\begin{array}{l}x^{2} \\
0\end{array}$} & \multirow{2}{*}{$\begin{array}{c}\mathrm{df} \\
1\end{array}$} & \multirow{2}{*}{$\begin{array}{c}\mathrm{p} \\
0.530\end{array}$} \\
\hline & 100 & 80.1 & 11 & 30.9 & & & & & & \\
\hline England & 90 & 74.4 & 13 & 28.6 & 103 & -15.6 & $\mathrm{~F} / \mathrm{H}$ & 33 & 1 & $<10^{-7}$ \\
\hline Hungary & 42 & 56.3 & 36 & 21.7 & 78 & 14.3 & $\mathrm{~F} / \mathrm{S}$ & 48 & 1 & $<10^{-11}$ \\
\hline \multirow[t]{3}{*}{ Spain } & 33 & 54.2 & 42 & 20.8 & 75 & 21.2 & $\mathrm{E} / \mathrm{H}$ & 26 & 1 & $<10^{-6}$ \\
\hline & 265 & & 102 & & 367 & & $\mathrm{E} / \mathrm{S}$ & 39 & 1 & $<10^{-9}$ \\
\hline & & $\begin{array}{c}x^{2} \\
73.4\end{array}$ & $\begin{array}{c}\mathrm{df} \\
3\end{array}$ & $\begin{array}{c}\mathrm{p} \\
10^{-15}\end{array}$ & & & $\mathrm{H} / \mathrm{S}$ & 1 & 1 & 0.223 \\
\hline
\end{tabular}

Questioning

\begin{tabular}{|c|c|c|c|c|c|c|c|c|c|c|}
\hline \multirow[b]{2}{*}{ Flanders } & OA & EA & $\mathrm{OP}$ & EP & \multirow{2}{*}{$\begin{array}{c}\text { Total } \\
111\end{array}$} & OP-EP & \multicolumn{2}{|r|}{$x^{2}$} & $\mathrm{df}$ & \multirow{2}{*}{$\begin{array}{c}\mathrm{p} \\
<10^{-12}\end{array}$} \\
\hline & 57 & 56.3 & 54 & 54.7 & & -0.7 & $\mathrm{~F} / \mathrm{E}$ & 54 & 1 & \\
\hline England & 97 & 52.2 & 6 & 50.8 & 103 & -44.8 & $\mathrm{~F} / \mathrm{H}$ & 32 & 1 & $<10^{-7}$ \\
\hline Hungary & 10 & 39.5 & 68 & 38.5 & 78 & 29.5 & $\mathrm{~F} / \mathrm{S}$ & 9 & 1 & 0.003 \\
\hline \multirow[t]{3}{*}{ Spain } & 22 & 38.0 & 53 & 37.0 & 75 & 16.0 & $\mathrm{E} / \mathrm{H}$ & 139 & 1 & $<10^{-31}$ \\
\hline & 186 & & 181 & & 367 & & $\mathrm{E} / \mathrm{S}$ & 90 & 1 & $<10^{-20}$ \\
\hline & & $\begin{array}{c}x^{2} \\
158.6\end{array}$ & $\begin{array}{c}\mathrm{df} \\
3\end{array}$ & $\begin{array}{c}\mathrm{p} \\
10^{-33}\end{array}$ & & & $\mathrm{H} / \mathrm{S}$ & 6 & 1 & 0.011 \\
\hline
\end{tabular}

Table 7: Results of cross tabulations for the observed absence (OA), expected absence (EA), observed presence (OP) and expected presence (EP) for three didactic strategies identified by chi-square tests (seen below the cross tabulations) as representing significantly different proportional variation by nationality. Alongside can be seen the results of pair-wise chi-square tests. Bonferroni's correction indicates that only probabilities smaller than 0.0017 should be viewed as significant.

\subsection{An alternative view of the data}

The above corroborates the existence of the national script but offers little in respect of evaluating its robustness. Is it the case, as Schmidt et al. (1996) assert, that differences across systems are greater than differences within? The following is an attempt to address this question. Unlike the above, we needed a process by which four groups of episodes reflecting the number of participant countries - could be created that privileged the properties of the data rather than pre-determined categories like nationality. Each of these four groups could then be tested for some measure of congruence with the different national scripts. In this way the strength of a national script and the degree to which individual teachers strayed beyond it could be determined. 
Conceptual knowledge

Derived knowledge

Structural knowledge

Procedural knowledge

Mathematical efficiency

Problem solving

Reasoning

Activating prior knowledge

Exercising prior knowledge

Explaining

Sharing

Exploring

Coaching

Assessing or evaluating

Motivating

Questioning

Differentiating

Episodes in the cluster
First application

Cluster number

\begin{tabular}{|cccc|}
\hline 1 & 2 & 3 & 4 \\
100 & 92 & 4 & 55 \\
0 & 9 & 0 & 1 \\
6 & 35 & 7 & 5 \\
71 & 43 & 100 & 35 \\
13 & 27 & 18 & 4 \\
38 & 24 & 18 & 4 \\
23 & 64 & 13 & 8 \\
6 & 32 & 16 & 19 \\
2 & 3 & 4 & 9 \\
49 & 68 & 47 & 51 \\
46 & 99 & 65 & 44 \\
9 & 2 & 4 & 1 \\
99 & 37 & 80 & 1 \\
13 & 9 & 38 & 26 \\
28 & 29 & 44 & 13 \\
27 & 90 & 51 & 3 \\
10 & 1 & 9 & 3 \\
\hline 96 & 139 & 55 & 77 \\
\hline & & &
\end{tabular}

Fifth application

Cluster number

\begin{tabular}{|cccc|}
\hline 1 & 2 & 3 & 4 \\
60 & 100 & 92 & 4 \\
1 & 0 & 9 & 0 \\
6 & 6 & 36 & 5 \\
37 & 70 & 43 & 98 \\
5 & 13 & 29 & 16 \\
5 & 36 & 26 & 18 \\
7 & 22 & 68 & 12 \\
20 & 6 & 33 & 14 \\
12 & 1 & 2 & 2 \\
42 & 50 & 71 & 53 \\
51 & 46 & 99 & 61 \\
1 & 10 & 2 & 4 \\
0 & 100 & 39 & 79 \\
25 & 13 & 8 & 39 \\
13 & 27 & 32 & 42 \\
11 & 27 & 89 & 49 \\
0 & 11 & 1 & 12 \\
\hline 83 & 94 & 133 & 57
\end{tabular}

Table 8: Percentage of episodes coded for each observable learning outcome and didactic strategy for each of the clusters identified by the first and the fifth of the 4 means cluster analyses.

In this respect, a cluster analysis, whose purpose is to group, or cluster, objects "in such a way that the profiles of the objects in the same clusters are very similar and the profiles of objects in different clusters are quite distinct" (Fil \& Dubus, 2005, p. 293), presented attractive possibilities. Clustering is usually achieved by one of two approaches, both of which assume that measures exist for determining the closeness of one object to another. The manner in which project episodes had been coded facilitated their being construed as vectors and the Euclidean metric used. In respect of our analysis, a partitional, or k-means, approach was adopted not only because it assumes a predetermined number of clusters but also because "since it directly calculates the k clusters, has more flexibility in identifying the clusters than hierarchical methods" (Maxwell, Pryor \& Smith, 2000, p. 25). To each of these initial clusters a randomly determined episode is assigned as the cluster centre. Each remaining episode is then assigned to the cluster to whose centre it is closest. The codes of all the episodes in each cluster are then averaged to form a new cluster centre. The process is then repeated with each episode being re-assigned according to which of the new centres it is now closest. This process is iterated until no further movement occurs (Carver, Fuchs, Jantzen, \& Kelso, 2002; Maxwell, et al., 2002; Watters, 2002).

The major problem, due to the random generation of the initial cluster centres and the likelihood that two "elements that are very close can be classified in two different clusters" 
(Fil \& Dubus, 2005, p. 293), lies in the likelihood of different outcomes emerging from the iterations. However, judicious use of analyses of variance and correlations should facilitate researchers' optimising their solutions (Fil \& Dubus, 2005; Kronthaler, 2005; Maxwell et al., 2002). In this particular case the following unsupervised approach was adopted, where "unsupervised clustering imposes no a priori assumptions about where the natural clusters are..., represents a bottom-up approach to the analysis and is most commonly used in exploratory analysis" (Maxwell et al., 2002, p. 23).

Five separate unsupervised analyses, each creating four clusters, were undertaken and the cluster memberships recorded in the data file as numbers between one and four. Had two analyses converged on identical solutions then a perfect correlation between the two memberships would have been achieved. However, the random nature of the process means that identical clusters may have been allocated different numbers. To overcome this problem the frequencies for each code were calculated for each cluster. By comparing the characteristics of each cluster in one set with those of another, similar clusters were identified and relabelled. By way of an example, the figures of Table 8 show the frequencies for each code for the clusters of both the first and the fifth application of the initial clustering process. It can be seen clearly that the characteristics of the first cluster of the first application are almost identical to those of the second cluster of the fifth application. Similarly, application one, cluster two is similar to application five, cluster three and so on. Initially, based on 367 episodes, the correlation between the cluster memberships of the first and the fifth application was -0.058 . Once relabelled, the correlation was 0.912 . This process was repeated pair wise across the five applications. The smallest of these revised correlations was 0.738 and the mean was 0.791 . Such figures appear to warrant a conclusion that each of the five applications had converged on a similar set of clusters.

The cluster analysis, in this case the first application, which yielded the most consistently high correlations with each of the other analyses, was selected for further examination. The figures of Table 8 show that each cluster of the first application has well defined characteristics. For example, in respect of observable learning outcomes, the episodes of cluster two with their emphases on learners' conceptual knowledge and reasoning, supported by frequent opportunities for procedural knowledge, structural knowledge, efficiency and problemsolving contrast greatly with the observed objectives of the episodes of cluster three which are dominated by procedural knowledge and a hint of efficiency and problem-solving. In short, while space prevents a detailed analysis of the various cluster characteristics it is hoped that the reader can see that each cluster presents very different perspectives on mathematics educational expectations and the means by which those expectations are realised from the others. The importance of this article lies in establishing the extent to which the coding structure of a cluster aligns with the script of a particular country. Consequently, further cross tabulations and chi-square tests were undertaken. The results of these tests (Table 9) show not only that the membership of each cluster drew on episodes from all project countries but also that it drew on them in significantly different proportions. For example, the first cluster could be construed as reflecting episodes common to both Flanders and Hungary but rare elsewhere. Cluster two can be viewed as a European cluster rarely seen in England, cluster three an Anglo-Spanish cluster infrequent in Flanders and rare in Hungary while English episodes dominate those of cluster four in which Hungarian and Spanish episodes are rarities. In short, with the exception of cluster four, almost half (48\%) of whose episodes were English, all clusters lent themselves to a description drawing in similar proportions on episodes from at least two countries. 


\begin{tabular}{|c|c|c|c|c|c|c|c|c|c|}
\hline Observed & 51 & 11 & 52 & 25 & \multirow{4}{*}{139} & & $x^{2}$ & $\mathrm{df}$ & $\mathrm{p}$ \\
\hline Expected & 42.0 & 39.0 & 29.5 & 28.4 & & & 122.0 & 9 & $<10^{-21}$ \\
\hline \multirow{2}{*}{$\begin{array}{c}\text { O-E } \\
\text { Observed }\end{array}$} & 9.0 & -28.0 & 22.5 & -3.4 & & & & & \\
\hline & 18 & 6 & 17 & 14 & & & & & \\
\hline Expected & 16.6 & 15.4 & 11.7 & 11.2 & \multirow[t]{3}{*}{55} & \multicolumn{4}{|c|}{ Pair-wise tests } \\
\hline \multirow{2}{*}{$\begin{array}{c}\text { O-E } \\
\text { Observed }\end{array}$} & 1.4 & -9.4 & 5.3 & 2.8 & & \multirow[b]{2}{*}{$\mathrm{F} / \mathrm{E}$} & $x^{2}$ & $\mathrm{df}$ & $\mathrm{p}$ \\
\hline & 16 & 49 & 4 & 27 & & & 53.5 & 3 & $<10^{-10}$ \\
\hline Expected & 29.0 & 26.9 & 20.4 & 19.6 & 96 & $\mathrm{~F} / \mathrm{H}$ & 17.5 & 3 & $\begin{array}{c}0.000 \\
5\end{array}$ \\
\hline O-E & -13.0 & 22.1 & -16.4 & 7.4 & \multirow{4}{*}{77} & $\mathrm{~F} / \mathrm{S}$ & 14.0 & 3 & $\begin{array}{c}0.002 \\
9\end{array}$ \\
\hline Observed & 26 & 37 & 5 & 9 & & $\mathrm{E} / \mathrm{H}$ & 103.7 & 3 & $<10^{-21}$ \\
\hline Expected & 23.3 & 21.6 & 16.4 & 15.7 & & $\mathrm{E} / \mathrm{S}$ & 29.2 & 3 & $<10^{-5}$ \\
\hline $\mathrm{O}-\mathrm{E}$ & 2.7 & 15.4 & -11.4 & -6.7 & & $\mathrm{H} / \mathrm{S}$ & 30.2 & 3 & $<10^{-5}$ \\
\hline Totals & 111 & 103 & 78 & 75 & 367 & & & & \\
\hline
\end{tabular}

Table 9: Cross tabulation, including both observed (O) and expected (E) outcomes for each cluster's membership by nationality. Included, also, are the differences between the observed and the expected values (O-E) and the results of a chi-square test undertaken to establish the significance of any differences. Additionally pair-wise tests have been undertaken to determine the significance of any differences between countries. Bonferroni's correction indicates that only probabilities smaller than 0.0017 should be viewed as significant.

To examine whether or not teachers' episodes fell consistently into particular clusters, further analyses were undertaken. The figures of Table 10 show that the episodes of all teachers fell into at least two clusters, with those of the majority falling into all four, and that this distribution was unlikely to be due to chance. With a simple majority as an indicator, it can be seen that eight teachers - Flemish 3 for example - tend to a dominant mode of working, while others - Spanish 3 for example - work in constantly varying ways. In respect of the particular questions of this article, the figures suggest that even when the episodes of a teacher point to a particular style, not all teachers from the same country align with the same style. For example, two of the English teachers seem cluster three dominant while the remaining two seem cluster four dominant.

In summary, each of the four clusters presents a diverse perspective on the aims of mathematics teaching and the means by which they are achieved. The episodes of all project teachers, irrespective of nationality, were distributed across the clusters although the majority tended towards a norm which was not always shared by teachers from the same country.

\section{Discussion}

It is important to acknowledge that we did not begin this project with entirely open minds as much of our previous work had already pronounced in favour of a national script (Andrews, 2007a; Andrews \& Hatch, 2000). However, the two approaches to data analysis, predetermined categorisation by nationality and unsupervised cluster analyses, have provided warrants for both national and global scripts respectively.

In respect of the national script, the analysis by country, despite similar emphases on conceptual and procedural knowledge and didactic strategies like explaining and sharing, shows well-defined differences which were unlikely to be due to chance. Moreover, despite a dearth of previous research examining the mathematics didactic traditions of Flanders or Spain, there is sufficient research examining mathematics teaching in England and Hungary to 
confirm that the above reflect well-established patterns of teacher expectation and behaviour; whether it is the collectively managed intellectually challenging experience of the Hungarian classroom (Andrews, 2003, Andrews \& Hatch, 2000), or the intellectually simplified (Haggarty \& Pepin, 2002; Jennings \& Dunne, 1996) and technique oriented experience of the English (Kaiser, 2002; Leung, 1995).

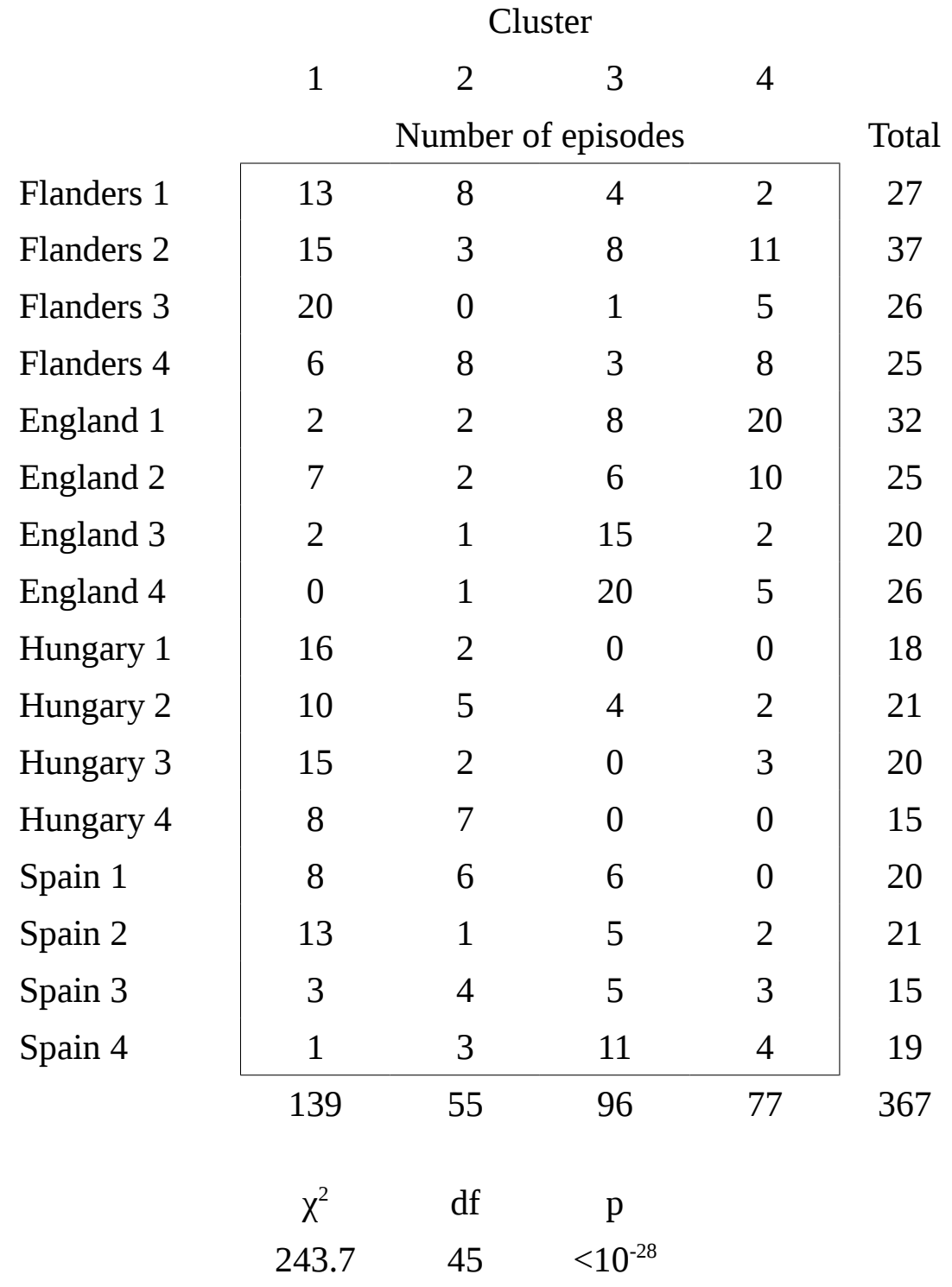

Table 10: Cross tabulations showing the distribution of episodes across clusters (1 through 4) for each teacher's (1 through 16) lessons.

In terms of the global script the evidence points not to one but several. Like the national scripts, each presents a well defined perspective on mathematics teaching and learning but fails to offer unequivocal support for the national script as no single cluster was so dominated by the episodes of one country as to be representative of it. Moreover, the spread of individual teachers' episodes across clusters alludes to variation in practice that challenges the robustness of the national script, particularly when set against the findings that the episodes of most teachers tended towards some sense of norm which did not always find resonance in those of other teachers from the same country. This provokes the question, are such differences due to shifts in practice brought about by, say, day-to-day factors like the time of day lessons are 
taught (Stigler \& Hiebert, 1999) or a genuine lack of robustness in the national script due, perhaps, to increasing teacher mobility and, as LeTendre et al. (2001) speculate, the increasing internationalisation of teaching?

In reflecting on our methods we believe that although the data set is small, it was collected and coded systematically, with a number of key variables controlled that had not been controlled in earlier studies. Each lesson yielded sufficient episodes for us to examine how teachers in project countries conceptualise and present mathematics to their learners. This process was facilitated by generic codes, developed over a year and related to a small number of observable learning objectives and didactic strategies, which allowed for a meaningful comparison of teachers' actions. This contrasts substantially with other studies. LeTendre et al. (2001) and Baker and LeTendre (2005) examined school level variables that offered little opportunity for discrimination while those examined by Givvin et al. (2005) were (comparatively) many and too tightly focused to discriminate helpfully. In this regard it is interesting that even from within the TVS team, there were concerns that the TVS codes had failed to acknowledge adequately the interactions between procedural knowledge and conceptual knowledge (Hiebert \& Handa, 2004). We feel confident that such problems, due not only to the manner in which our codes were generated but also the time-independent manner of their application, would not arise if colleagues attempted to replicate our work.

This latter observation alludes to one of the significant findings of our work; that the use of generic, time-independent codes, has essentially redefined the teaching script. Our data indicate that the teaching script is more effectively construed as a functional not a temporal construct, defined more by the things teachers do than when they do them. This construal enables us to reconcile many of the supportive arguments for both scripts, not least because all project teachers, in one way or another, adhered to at least one of each. That said, examining what teachers do in their classrooms is only part of the story. The fuller account necessitates our understanding why teachers do what they do, and this, we argue, requires research that foregrounds the individual's voice in the manner of a recent study of English and Hungarian teachers' beliefs about the nature of mathematics and its privileged curricular place (Andrews, 2007a) and how this is influenced by institutional and systemic constraints like the numbers of classes teachers are expected to teach or non-teaching responsibilities (Baker \& LeTendre, 2005). Thus, in conclusion, and acknowledging that no research can yield a complete understanding, our data suggest that episodically-focused, generically-coded videobased analyses may be more successful in facilitating our understanding of teachers' mathematics-related behaviour than temporally-focused, specifically-coded video-based analyses.

\section{Acknowledgement}

The mathematics education traditions of Europe (METE) project team gratefully acknowledges the financial support of the European Union, Socrates Action 6.1 programme, project code 2002-5048.

\section{References}

Ahlf, W., \& Heise, S. (2005) Sediment Toxicity Assessment: rationale for effect classes. Journal of Soil and Sediments, 5 (1), 16-20.

Andrews, P. (2003). Opportunities to learn in the Budapest mathematics classroom. International Journal of Science and Mathematics Education 1 (2), 201-225.

Andrews, P. (2007a). The curricular importance of mathematics: a comparison of English and Hungarian teachers' espoused beliefs. Journal of Curriculum Studies 39 (3), 317-338. 
Andrews, P. (2007b). Negotiating meaning in cross-national studies of mathematics teaching: kissing frogs to find princes. Comparative Education 43 (4), (forthcoming).

Andrews, P., \& Hatch, G. (2000). A comparison of Hungarian and English teachers' conceptions of mathematics and its teaching. Educational Studies in Mathematics 43 (1), 3164.

Baker, D., and LeTendre (2005). National differences, global similarities: World culture and the future of schooling. Stanford: Stanford University Press.

Carver, F., Fuchs, A., Jantzen, K., \& Kelso, J. (2002). Spatiotemporal analysis of the neuromagnetic response to rhythmic auditory stimulation: rate dependence and transient to steady-state transition. Clinical Neurophysiology 113, 1921-1931.

Clarke, D. (2006). The LPS research design. In D. Clarke, C. Keitel \& Y. Shimizu (Eds.), Mathematics classrooms in twelve countries: The insider's perspective (pp. 15-36). Rotterdam: Sense Publishers.

Clarke, D., Mesiti, C., Jablonka, E., \& Shimizu, Y. (2006). Addressing the challenge of legitimate international comparisons: Lesson structure in the USA, Germany and Japan. In D. Clarke, J. Emanuelsson, E. Jablonka and I.A.C. Mok (Eds.), Making connections: Comparing mathematics classrooms around the world (pp. 23-45). Rotterdam: Sense Publishers.

Cogan, L., \& Schmidt, W. (1999). An examination of instructional practices in six countries. In G. Kaiser, E. Luna \& I. Huntley (Eds.), International comparisons in mathematics education (pp. 68-85). London: Falmer.

Fil, C., \& Dubus, L. (2005). Winter climate regimes over the North Atlantic and European region in the ERA40 reanalysis and DEMETER seasonal hindcasts. Tellus 57A, 290-307

Givvin, K., Hiebert, J., Jacobs, J., Hollingworth, H., \& Gallimore, R. (2005). Are there national patterns of teaching? Evidence from the TIMSS 1999 video study. Comparative Education Review 49 (3), 311-343.

Haggarty, L., \& Pepin, B. (2002). An investigation of mathematics textbooks and their use in English, French and German classrooms: who gets an opportunity to learn what? British Educational Research Journal 28 (4), 567-590.

Hiebert, J., \& Handa, Y. (2004). A modest proposal for reconceptualizing the activity of learning mathematical procedures. Paper presented to the annual meeting of the American Educational Research Association, San Diego, April, 2004.

Hiebert, J., Gallimore, R., Garnier, H., Bogard Givvin, K., Hollingsworth, H., Jacobs, J., MiuYing Chui, A., Wearne, D., Smith, M., Kerstling, N., Manaster, A., Tseng, E., Etterbeek, W., Manaster, C., Gonzales, P., \& Stigler, J. (2003). Teaching mathematics in seven countries: results from the TIMSS 1999 video study. Washington: National Center for Educational Statistics.

Hufton, N., \& Elliott, J. (2000). Motivation to learn: the pedagogical nexus in the Russian school: some implications for transnational research and policy borrowing. Educational Studies 26 (1) 115-136.

Jennings, S., \& Dunne, R. (1996). A critical appraisal of the National Curriculum by comparison with the French experience. Teaching Mathematics and its Applications 15 (2), 49-55.

Kaiser, G. (2002). Educational philosophies and their influence on mathematics education an ethnographic study in English and German mathematics classrooms. Zentralblatt für Didaktik der Mathematik 34, 241-257. 
Knipping, C. (2003). Learning from comparing: A review and reflection on qualitative oriented comparisons of teaching and learning mathematics in different countries. Zentralblatt für Didaktik der Mathematik 35 (6), 282-293.

Kronthaler, F. (2005). Economic capability of East German regions: results of a cluster analysis. Regional Studies 39 (6), 22-38.

LeTendre, G. Baker, D. Akiba, M. Goesling, B., \& Wiseman, A. (2001). Teachers' work: Institutional isomorphism and cultural variation in the U.S., Germany, and Japan. Educational Researcher 30 (6), 3-15.

Leung, F. (1995). The mathematics classroom in Beijing, Hong Kong and London. Educational Studies in Mathematics 29 (3), 297-325.

Leung, F. (2001). In search of an East Asian identity in mathematics education. Educational Studies in Mathematics 47 (1), 35-51.

Maxwell, B., Pryor, F., \& Smith, C. (2002). Cluster analysis in cross-cultural research. World Cultures 13 (1), 22-38.

Osborn, M. (2004). New methodologies for comparative research? Establishing 'constants' and 'contexts' in educational experience. Oxford Review of Education 30 (2), 265-285.

Schmidt, W., Jorde, D., Cogan, L., Barrier, E., Gonzalo, I., Moser, U., Shimizu, K., Sawada, T., Valverde, G., McKnight, C., Prawat, R., Wiley, D., Raizen, S., Britton, E., \& Wolfe, R. (1996). Characterizing pedagogical flow: an investigation of mathematics and science teaching in six countries. Dordrecht: Kluwer.

Sharpe, K. (1997). The Protestant ethic and the spirit of Catholicism: ideological and institutional constraints on system change in English and French primary schooling. Comparative Education 33 (3), 329-348.

Stigler, J., \& Hiebert, J. (1999). The teaching gap. New York: The Free Press.

Stigler, J., Gonzales, P., Kawanaka, T., Knoll, S., \& Serrano, A. (1999). The TIMSS videotape classroom study. Washington, DC: National Center for Educational Statistics.

Tweed, R., \& Lehman, D. (2002). Learning considered within a cultural context: Confucian and Socratic approaches. American Psychologist 57 (2), 89-99.

Ulewicz, M., \& Beatty, A. (2001). The power of video technology in international comparative research in education. Washington DC: National Academy Press.

Watkins, D. (2000). Learning and teaching: a cross-cultural approach, School Leadership and Management 20 (2), 161-173.

Watters, P. (2002). Discriminating English word senses using cluster analysis. Journal of Quantitative Linguistics 9 (1), 77-86.

Paul Andrews works in the Faculty of Education at the University of Cambridge. He was director of the European Union-funded mathematics education traditions of Europe (METE) project. 